\title{
Tendencias, desafíos y respuestas en el tratamiento de los problemas de migración y adicciones
}

\author{
Elena Hedoux \\ Grupo de Cooperación para Combatir el Abuso y el Tráfico llícito de Drogas (Grupo Pompidou) \\ Consejo de Europa
}

Las variaciones en el desarrollo demográfico derivadas de los procesos migratorios muestran la necesidad de contar con enfoques especializados en la atención de la salud mental y el tratamiento de las adicciones, que se adecúen a las características de la población migrante, pues aunque los movimientos migratorios tienen lugar en contextos internacionales altamente globalizados, existen importantes diferencias entre las sociedades de origen y las de acogida, lo que dificulta los procesos de adaptación.

Estas variaciones no sólo son un desafío para los migrantes, sino también para los proveedores de servicios profesionales y los encargados de formular políticas públicas en los países receptores, incluyendo a los que se desenvuelven en el campo de la salud, en específico la salud mental y el tratamiento para el uso y abuso de sustancias, ya que las concepciones sobre prevención, tratamiento y ética médica, así como la percepción sobre el rol del personal médico y los servicios sociales suelen discrepar.

En estos últimos años, Europa afronta una gran afluencia de migrantes, entre quienes se distinguen dos grandes grupos: los ilegales y los refugiados. En el primero se pueden encontrar personas que arriban al continente con la intención explícita de ganar dinero y enviarlo a sus países de origen; estas remesas se han convertido en una ayuda económica estable para un gran número de ciudadanos de África, Asia y Europa del Este. Algunos de los problemas que plantea este grupo se relacionan con las redes de delincuencia organizada que trafican con los migrantes ilegales y con la dificultad de llevar a cabo procesos de repatriación a los países de origen, debido a la tendencia de los migrantes a destruir sus documentos de identidad una vez que se encuentran en Europa.

El segundo grupo está integrado por refugiados de guerra provenientes principalmente de Medio Oriente, quienes son recibidos de forma temporal en los países europeos y deben regresar una vez que los conflictos armados en sus lugares de origen concluyan. Este grupo plantea dificultades como la de estimar el número de refugiados por arribar y la incertidumbre sobre su retorno una vez que la situación política en sus lugares de origen se estabilice.

A fin de contemplar el movimiento migratorio en Europa desde una perspectiva más amplia, es conveniente recordar que el Acuerdo de Schengen ha impulsado la creación de un espacio libre de viaje y sin controles fronterizos, que no incluye ni considera un acuerdo formal sobre cómo debe abordarse la afluencia de refugiados a una escala tan alta como la que en la actualidad se registra. A causa de la falta de esta resolución, los migrantes pueden dirigirse con libertad al país que, consideran, cubre mejor sus necesidades, ya sea porque cuentan con un sistema de seguridad social muy extenso o por la existencia de sistemas jurídicos que les permiten permanecer por una mayor cantidad de tiempo. Estas situaciones han derivado en una distribución desequilibrada de refugiados entre los países, provocando que algunos sigan recibiendo a un gran número de ellos, pese a su incapacidad para alojarlos.

Esta desproporción en el número de migrantes es cada vez más visible y, cuando se combina con otros problemas, propicia el desarrollo y el fortalecimiento en las poblaciones locales de un estigma negativo hacia los migrantes. Entre las dificultades asociadas con este

\section{Autor de correspondencia:}

Elena Hedoux. Responsable de programas, Grupo Pompidou, El Consejo de Europa. Correo electrónico: elena.hedoux@coe.int www.coe.int/pompidou 
fenómeno se puede nombrar el hecho de que los sistemas sociales actuales europeos no fueron diseñados para hacer frente al alto flujo de migrantes y refugiados; asimismo, hay que mencionar la complicada integración socioeconómica de los migrantes que carecen de habilidades, conocimientos y experiencia suficientes para incorporarse al mercado laboral de los países de acogida -aún con la reciente implementación de programas especiales de formación-, así como el alto riesgo de que se involucren en actividades delictivas relacionadas, muchas veces, con el tráfico de drogas. Además, se debe considerar que los países destino lidian con problemas previos, como las altas tasas de desempleo entre la población nacional, que dificultan la apertura de oportunidades de trabajo para los migrantes. La falta tanto de actividad laboral como de integración social conduce, en muchas ocasiones, a un aumento en el número y la frecuencia de los problemas de salud y en la incidencia de enfermedades mentales como el abuso de sustancias, que derivan en un alto costo social.

Si bien en muchos países europeos existe un sistema sólido de bienestar social, que incluye el tratamiento y la rehabilitación para enfermedades mentales y el uso de drogas, son escasos los sistemas de apoyo eficaces para los migrantes consumidores (en especial los irregulares), que tomen en consideración sus especificidades sociales, psicológicas y culturales, así como las necesidades propias de la migración y la particular experiencia de los refugiados. Es esencial la consideración de estas condiciones para proporcionar servicios especializados de la más alta calidad.

En este sentido, el Grupo Pompidou comenzó el estudio de los problemas transculturales relacionados con el consumo de drogas hace más de 10 años. En ese periodo se preparó un manual para profesionales que trabajan con usuarios de drogas de diferentes orígenes étnicos y culturales; se organizaron visitas de estudio a países con una larga experiencia en la diversidad cultural; se coordinó una conferencia internacional, a petición de la Federación de Rusia, en la que la directora de Centros de Integración Juvenil, la maestra Carmen Fernández Cáceres, compartió la experiencia mexicana en intervenciones especializadas de prevención de drogas dirigidas a migrantes y poblaciones de minorías étnicas, entre otros esfuerzos. Como resultado de estas iniciativas, se impulsó un tratamiento especializado que considera, ante todo, la sensibilidad cultural; en este contexto, se vuelve fundamental la consideración de que un comportamiento aceptable o deseable en una cultura, puede ser grosero e inaceptable en otra, situación que impacta la atención sanitaria.

Estas diferencias son remarcadas cuando se comparan algunos aspectos de las sociedades occidentales y orientales. Por ejemplo, en la cultura moderna occidental se da un lugar privilegiado al individualismo, existe un sistema de valores basado en derechos y privilegios básicos y se coloca a la igualdad como la base de la estructura social. Los individuos occidentales suelen ser expresivos en cuanto a sus ideas y emociones; encuentran una fuente importante de satisfacción en la autoafirmación y la autorrealización; su comportamiento está influenciado por la personalidad; y presentan altos grados de autocontrol.

En contraste, la cultura oriental tradicional fomenta el desarrollo colectivo a partir de la unidad familiar; posee un sistema de valores asentado en obligaciones y deberes y una estructura social configurada en un sistema jerárquico. Los individuos orientales suelen ser modestos, limitan la expresión de sus emociones y sólo comparten pensamientos completos; su principal fuente de satisfacción radica en el aprecio social; y su comportamiento individual está influenciado por las normas sociales y el control ejercido por la familia, la comunidad y la sociedad.

Estas diferencias radicales impactan, además de la esfera individual y social, el abordaje de la salud mental, pues mientras el tratamiento occidental es abierto, emplea métodos indirectos para llegar a las soluciones de los problemas y se basa en una relación igualitaria entre el terapeuta y el paciente, en el tratamiento oriental los terapeutas explican, instruyen y proporcionan soluciones directas a problemáticas determinadas, pues la relación entre terapeuta y paciente es similar a la de profesor-alumno. Otras diferencias se perciben en la actuación de los terapeutas: en la dinámica occidental se mantienen pasivos y se limitan a proporcionar consejos y realizar preguntas que fomenten que el paciente busque sus propias soluciones; mientras que en la oriental, los terapeutas son completamente activos, proporcionan instrucciones y órdenes y responden a las preguntas que ellos mismos elaboran.

Para planificar e implementar abordajes efectivos de tratamiento y rehabilitación social de usuarios de drogas procedentes de diferentes grupos étnicos es necesario considerar las especificidades culturales, las normas, los valores, las actitudes hacia el tratamiento y las expectativas sobre el papel de los profesionales, entre otros factores. Es importante, también, el establecimiento del diálogo con los migrantes y el respeto a su cultura.

Es posible que la integración de estos grupos se vea favorecida con el desarrollo y el fortalecimiento de competencias transculturales por parte de los profesionales y las instituciones que brindan los servicios de atención. Entendemos la competencia transcultural como la capacidad de trabajar con sensibilidad y eficacia en diversos contextos culturales, asegurando el respeto de los valores, las creencias y los estilos de comportamiento 
particulares de los migrantes, y adecuando los servicios a las necesidades sociales, culturales y lingüísticas de los individuos.

El desarrollo de las competencias profesionales transculturales requiere que los prestadores de servicios cuenten con habilidades de comprensión y comunicación sociocultural; deben conducir su actuación de manera profesional y establecer y mantener actitudes correctas dentro de los límites del tratamiento. Es fundamental que muestren siempre buena disposición para escuchar y entender a personas de orígenes diversos, enfocándose en ellas como personas y dejando de lado los estereotipos. En este sentido, es importante recordar que el respeto y la consideración de las diferencias pueden ser factores clave para lograr el éxito del tratamiento y la rehabilitación, así como para adecuar los servicios de asistencia social y médica.

Es fundamental que en el desarrollo de la atención y la prevención se consideren en todo momento las competencias transculturales. Asimismo, es necesario que el apoyo institucional y global se refleje en políticas, procedimientos y mecanismos de monitoreo y asignación de recursos financieros y humanos apropiados que contemplen al personal que trabaja directamente con los migrantes, a los encargados de la formación de profesionales, a los intérpretes y a otros expertos relacionados.

Recomendamos, además, que durante el proceso de establecimiento de organizaciones transculturales de ayuda y apoyo a los migrantes se considere la triada "quiénes son, qué hacen y a quién sirve", pues ayuda a las organizaciones a tener claridad en el momento de considerar a su población objetivo.
Considerando que las tendencias demográficas sugieren que los niveles de migración se mantendrán altos o que incluso aumentarán en los años siguientes, es importante sentar las bases para contar con un sistema de servicios transculturalmente competentes que puedan ayudar a los diferentes tipos de grupos de migrantes. Esto vuelve necesaria la adopción de una serie de medidas organizativas y prácticas que tenga como propósito el desarrollo de este sistema; entre ellas se cuenta el desarrollo de competencias transculturales a nivel organizacional, profesional y personal; así como la implementación de estrategias de gestión para organizaciones culturalmente adaptadas con objetivos, planes, procedimientos y personal capacitado para su implementación.

Es aconsejable recordar la importancia de la formación permanente de administradores, profesionales y personal auxiliar, enfocada en el desarrollo y el mejoramiento de sus competencias transculturales. Se debe considerar también la evaluación y el seguimiento continuo de los procesos de atención, con la finalidad de procurar la calidad de los servicios. Por último, hay que promocionar entre los migrantes la existencia de metodologías eficaces para atender el consumo de drogas, como los servicios de bajo umbral, el apoyo con interpretación y traducción y los grupos de autoayuda, entre otros.

Estas medidas contribuirán a mejorar el sistema transcultural de servicios competentes para los migrantes. Bajo la premisa de que al mejorar el sistema, mejorará la situación de estas personas.

Estrasburgo, Francia. 